\title{
Effects of Plant Growth Regulators on the Growth and Resistance Physiology of Banana Planting Big Seedlings
}

\author{
Li Na Huang, ${ }^{1,}$, Shimin Cheng ${ }^{1, b}$, Zhenrong Yang $^{1, c}$, Zengxian Zhao ${ }^{1, d}$, Zisi \\ $\mathrm{Xie}^{1, \mathrm{e}}$ and Shouxing $\mathrm{Wei}^{1, \mathrm{f}^{*}}$
}

\author{
${ }^{1}$ Tropical Crops Genetic Resources Institute, Chinese Academy of Tropical Agricultural \\ Sciences(CARTA)/ National Cultivar Improvement Center of Tropical Fruit Tree /Hainan Tropical \\ Fruit Engineering Technology Research Center , Danzhou,571737,China \\ a huanglinahappy@sina.com, b867944012@qq.com, c540953238@qq.com, \\ dghostmind@qq.com, ㅎ4043545@qq.com, 'shouxingwei@163.com
}

${ }^{*}$ The Corresponding author

\begin{abstract}
Keywords: Plant growth regulator; Banana provisonal planting seedling; Growth; Resistance physiological
\end{abstract}

\begin{abstract}
Take the ordinary banana transplanting seedlings as material, use potting experiment; take the seedlings that haven't been sprayed by plant growth regulator as the control group. In this paper, we study the effects of plant growth regulators on the growth, nutritional absorption and resistance physiology of banana planting big seedlings. The results show that compared with the control group, spraying gibberellin on the leaf can significantly increase the seedling height by $27.75 \%$, and increase chlorophyll content of $19.11 \%$; effectively reduce MDA content of the leaf, increase proline content, increase SOD content of the leaf by $21.94 \%$, and increase POD content of $82.13 \%$; compared with the control group, Spraying $\alpha$-sodium naphthalene acetate can significantly increase the seedling diameter by $17.67 \%$, increase the seedling dry matter cumulant of $16.11 \%$, and increase the strong-seedling index by $21.49 \%$; Improve nitrogen and phosphorus nutrient uptake, increased by $9.95 \%$ and $9.95 \%$ respectively. So in breeding process of banana planting seedlings, in order to get robust provisonal planting seedlings, we should consider to spray the intermixtures of gibberellin and $\alpha$-sodium naphthalene acetate, or spray these two regulators at specific intervals.
\end{abstract}

Fostering healthy and strong banana planting seedling that have strong adverse resistance is the foundation of stable and high banana yield. These days, the banana seedling transplanting, mostly happens in the summer and fall, and is accompanied by problems that the recuperating period is long, the seedlings grow weakly, the survival rate is low, which lead to irregularity of bananas plants growth in later stage. [1-2]. Every year, the cold in in winter and spring would damage banana production to the banana production areas in China, resulting in reduction of output, or even no harvest, which has become the factors restricting the development of the banana industry [3-4]. In addition, banana harvest time is too concentrated in China, which results in low banana prices, and discourage the enthusiasm of farmers [5-8]. So how to realize the seedling efficient transplanting, avoid the cold damage and adjust the harvest period is the key to high quality production of bananas. The current research has shown that on the basis of cultivating strong banana secondary planting seedlings, cultivate older planting seedlings, then transplant the seedlings to fields, which can effectively shorten seedling stage in the field, and avoid the harm from cold in the winter and spring, so as to realize the banana high quality production [6-8]. Therefore, the research on technology to foster robust older planting seedlings of banana is of great significance for the banana production.

Studies have shown that gibberellin, multi-effect azole, $\alpha$-sodium naphthalene acetate, Compound sodium nitrophenolate and diethyl aminoethyl hexanoate etc., are widely involved in the regulation of plant growth and development[8-13]. Gibberellin can promote plant growth, destroy the apical dominance, promote the growth of lateral branches, and break the dormancy, and regulate the flowering. Morphologically praying gibberellin on the crops would significantly promote the 
stem elongation, and within a certain range of concentration, as concentration is increased, the enhancement is increased [14]. Dipping the seedling root in Multi-effect azole can increase the survival rate. During seedling stage, spraying it on the stems can control the growth of the top, promote the growth of the lower part of the seedling, control the height of the seedling, promote root growth, improve the quality of the seedlings [15]. High purity of $\alpha$-sodium naphthalene acetate can reduce the premature flower and fruit abscission rate, promote flowering and fruit setting, effective improve resilience of crops (16-17). Zi-long zhang, et al., [18] found diethyl aminoethyl hexanoate can significantly promote the soluble protein content of rice seedling under low temperature stress. On the basis of reduction of MDA content, enhance activity of protective enzymes such as SOD and POD etc.. However, the application of plant growth regulators in banana planting seeding breeding, especially in cultivating of older banana provisional planting seedlings, has rarely been reported, and related researches haven't been seen. Long Yifei [7] and Zhang Xin-ling [8] study the effects of gibberellin and multi-effect azole on banana secondary seedling cultivation, and the study is limited to the growth index and index of nutrient, and hasn't referred to the study of planting seedling adverse resistance. Therefore, in this experiment, we select 5 kinds of common plant growth regulators, spray in the process of cultivation of older banana provisional planting seedlings, make comprehensive evaluation of effects of different plant growth regulators on the cultivation of older banana provisional planting seedlings, in order to select the appropriate regulators, banana provisional planting went to this experiment will provide theoretical basis for cultivating technology of older banana provisional planting seedlings.

Experimental materials. The crops selected for experiment: a Brazilian breed banana transplanting seeding (six leaves and one shoot), provided by Seedling Tissue Culture Center of Chinese Academy of Tropical Agricultural Sciences ; The basin selected: black nutrition cup (specification (straight stem x height) : $16 \mathrm{~cm} \times 14 \mathrm{~cm}$ ).

The media selected: coconut chaff, physical and chemical properties of bulk density: 18.69 g/cm3, total porosity: $79.65 \%$, PH: 5.81 , organic matter: $64.38 \%$, alkali-hydrolyzable nitrogen: $357.42 \mathrm{mg} / \mathrm{kg}$, rapid available phosphorus: $821.66 \mathrm{mg} / \mathrm{kg}$, rapidly-available potassium: 28976.53 $\mathrm{mg} / \mathrm{kg}$.

The fertilizers selected: urea $(46 \% \mathrm{~N})$, potassium chloride (K2O 60\%), compound fertilizer (15-15-15).

Plant growth regulators: gibberellin (GA3) (purity 98\%), multi-effect azole (PP333) (purity 98\%), Compound sodium nitrophenolate (98\% purity), diethyl aminoethyl hexanoate (DA - 6) purity (98\%), $\alpha$-sodium naphthalene acetate (purity 98\%).

The method applied in the experiment. Use types of plant growth regulators as influence factors, set 5 processing approaches by using gibberellin, multi-effect azole, compound sodium nitrophenolate, diethyl aminoethyl hexanoate, $\alpha$-sodium naphthalene acetate, use the crops that haven't handled plant growth regulator as the control group. Use Spraying concentration of plant growth regulator of $20 \mathrm{mg} / \mathrm{L}$, evenly spraying on the front side to the back of leaves till the plant growth regulator becomes a water drop. When spraying, use plastic film to separate this processing procedure from the part that has been dealt with by other processing, to prevent cross contamination. For the control group that hasn't been sprayed by plant growth regulator, spray the same amount of water on it at the same time. Transplant the seedlings on July 9, 2015. After the seedlings recuperate, do a treatment every 12 days, for a total of 5 times. 7 days after each treatment, measure the growth indexes. Set 15 banana planting seedlings for a group to observe, make a measurement every 10 days. On September 25, the banana planting seedlings have basically reached the standard of the older seedlings (with $13 \sim 15$ of leaves) [19], when we make a unified recovery. Seeding sampling includes the sampling above the ground and the underground sampling; 9 older banana planting seedlings that are healthy and evenly growing, are randomly selected for sampling. then select mesophyll of the top second leave that has fully expanded, wrapped with aluminum foil, preserve it under the ultra-low temperature condition of - $80{ }^{\circ} \mathrm{C}$ after being frozen by liquid nitrogen, which is used for the determination of physiological indexes. 
During the experiment, ensure the water content at $60 \% \sim 80 \%$. In the process of the banana planting seedlings breeding, each crop of banana needs urea of $4.27 \mathrm{~g}$, potassium chloride of $1.61 \mathrm{~g}$, compound fertilizer of $7.49 \mathrm{~g}$, which is divided into seven times of spraying in the way of water and fertilizer,.

Methods and determination indexes. Leaf length, leaf width: use straightedge to measure the maximum length and the maximum width uniformly; Leaf area $=$ leaf length $\mathrm{x}$ leaf width $\mathrm{x}$ $0.76299+0.0266[7-8]$; Planting stem height: use straightedge to measure the distance uniformly from the surface of the media to the intersection of two leaves that have expanded; Planting stem diameter: the value is measured by Vernier caliper uniformly, at the position of $2 \mathrm{~cm}$ height from the surface of the media.[8] unified use Vernier caliper from substrate surface $2 \mathrm{~cm}$ readings [8]. of After crushing the sample, use - H2SO4 - H2O2 Digestion, then use indophenol blue colorimetry method to test $\mathrm{N}$, and use Mo-Sb colorimetric method to test $\mathrm{P}$, and use flame spectrophotometry method to test $\mathrm{K}[20]$.

Use anhydrous ethanol and acetone method to test chlorophyll content; Proline and malondialdehyde (MDA) content by using sulfosalicylic acid and glucosinolates barbituric acid determination method; Peroxidase (POD) and superoxide dismutase (SOD) activity, respectively by using guaiacol and nitroblue tetrazolium method $(21,22)$. Above physiological indexes to sample Fresh Weight (Fresh Weight, FW) as a base for said.

Data calculation and processing. We use Excel 2007 and software SPSS 13.0 for data processing and statistical analysis in this experiment.

\section{The results and analysis}

The effects of growth regulators on the growth of the older banana planting seedlings. As shown in table 1, compared with the controls, multi-effect azole can significantly reduce the stem height of banana planting seedlings ; Gibberellin, diethyl aminoethyl hexanoate, and $\alpha$-sodium naphthalene acetate can significantly increase the stem height of banana planting seedlings , in which gibberellin has the best effect, the height increased of $27.75 \%$ higher than that of the control group. $\alpha$-sodium naphthalene acetate can significantly increase the stem width of banana planting seedlings by $17.67 \%$ higher than the control group. As for the foliage area of the top three leave of the older banana planting seedlings, the results show that, except $\alpha$-sodium naphthalene acetate, all growth regulators significantly increase the leaf area in contrast to the control group. Thus, Gibberellin and diethyl aminoethyl hexanoate can obviously promote the stem height of banana planting seedlings and the growth of the top three leave of the older banana planting seedlings ; $\alpha$-sodium naphthalene acetate can promote the stem height and width of the older banana planting seedlings.

Table 1 The effects of plant growth regulator on banana planting seedlings growth

\begin{tabular}{ccccc}
\hline Treatment & $\begin{array}{c}\text { Stem height of } \\
\text { planting seedling } \\
(\mathrm{cm})\end{array}$ & $\begin{array}{c}\text { Stem width of } \\
\text { planting } \\
\text { seedling }(\mathrm{cm})\end{array}$ & $\begin{array}{c}\text { Top three leaf } \\
\text { area }\left(\mathrm{cm}^{2}\right)\end{array}$ & $\begin{array}{c}\text { New leaf } \\
\text { number }\end{array}$ \\
\hline The control group & $24.94 \pm 0.39 \mathrm{~d}$ & $2.32 \pm 0.06 \mathrm{~b}$ & $212.2 \pm 6.64 \mathrm{~b}$ & $7.2 \pm 0.4 \mathrm{a}$ \\
gibberellin & $31.86 \pm 0.75 \mathrm{a}$ & $2.39 \pm 0.05 \mathrm{~b}$ & $289.75 \pm 13.86 \mathrm{a}$ & $6.8 \pm 0.2 \mathrm{a}$ \\
multi-effect azole & $19.90 \pm 0.27 \mathrm{e}$ & $2.39 \pm 0.03 \mathrm{~b}$ & $283.07 \pm 10.78 \mathrm{a}$ & $7.4 \pm 0.4 \mathrm{a}$ \\
Compound sodium & $26.64 \pm 0.90 \mathrm{~cd}$ & $2.33 \pm 0.05 \mathrm{~b}$ & $279.33 \pm 12.14 \mathrm{a}$ & $7.4 \pm 0.4 \mathrm{a}$ \\
nitrophenolate & $28.88 \pm 0.81 \mathrm{~b}$ & $2.46 \pm 0.05 \mathrm{~b}$ & $290.82 \pm 13.87 \mathrm{a}$ & $7.4 \pm 0.2 \mathrm{a}$ \\
diethyl aminoethyl hexanoate & $28.06 \pm 0.75 \mathrm{bc}$ & $2.73 \pm 0.05 \mathrm{a}$ & $222.91 \pm 3.38 \mathrm{~b}$ & $7.2 \pm 0.4 \mathrm{a}$ \\
\hline a -sodium naphthalene acetate & & & & \\
\hline
\end{tabular}

Note: the values in the table represent the average \pm standard error, the lowercase letters in different columns mean significant differences between treatments $(\mathrm{P} \leq 0.05)$, use new multiple range method Duncan for multiple comparison, the same below.

The Effects of Growth Regulators on Dry Matter Cumulant and Nutrient Uptake of the Older Banana Planting Seedlings. As shown in table 2, compared with the control group, compound sodium nitrophenolate, diethyl aminoethyl hexanoate, and $\alpha$-sodium naphthalene acetate 
can all significantly increase the dry matter cumulant of banana planting seedlings, the dry matter cumulant increased by $13.19 \%$ on average, in which gibberellin has the best effect, the dry matter cumulant increased up to $16.11 \%$. As for nutrient uptake, compared with the control group, compound sodium nitrophenolate and $\alpha$-sodium naphthalene acetate can all significantly increase phosphorus absorption of banana planting seedlings, which is increased by $10.64 \%$. The different potassium uptake of various processing procedures of the older banana planting seedlings are shown as follows: The crops processed by $\alpha$-sodium naphthalene acetate and the control group have not significant difference, and the potassium uptake in these two cases are all higher than other processing procedures. It can be seen that, during the cultivation of the older planting banana seedlings, spraying $\alpha$-sodium naphthalene acetate is inductive to dry matter cumulant and nutrient uptake of the older banana planting seedlings.

Table 2 The Effects of Growth Regulators on Dry Matter Cumulant and Nutrient Uptake of the Older Banana Planting Seedlings.

\begin{tabular}{|c|c|c|c|c|}
\hline \multirow{2}{*}{$\begin{array}{c}\text { Treatme } \\
\text { nt }\end{array}$} & \multirow{2}{*}{$\begin{array}{l}\text { dry matter } \\
\text { cumulant } \\
\text { (g/each } \\
\text { crop) }\end{array}$} & \multicolumn{3}{|c|}{ nutrient uptake (mg/each crop) } \\
\hline & & $\mathrm{N}$ & $\mathrm{P}$ & $\mathrm{K}$ \\
\hline $\begin{array}{l}\text { The } \\
\text { control }\end{array}$ & $19.06 \pm 0.35$ & & & \\
\hline group & $\mathrm{c}$ & $238.86 \pm 3.55 b c$ & $55.25 \pm 1.08 \mathrm{bc}$ & $770.93 \pm 14.83 \mathrm{a}$ \\
\hline $\begin{array}{c}\text { gibberell } \\
\text { in }\end{array}$ & $\begin{array}{c}20.30 \pm 0.34 \\
b c\end{array}$ & & & \\
\hline multi-eff & $\begin{array}{c}\text { DC } \\
20.31 \pm 0.42\end{array}$ & $236.54 \pm 4.02 \mathrm{bc}$ & $54.46 \pm 2.11 \mathrm{bc}$ & $643.34 \pm 20.11 \mathrm{c}$ \\
\hline ect azole & $\mathrm{bc}$ & $226.02 \pm 4.94 \mathrm{c}$ & $51.18 \pm 0.78 \mathrm{c}$ & $651.5 \pm 13.04 \mathrm{bc}$ \\
\hline $\begin{array}{l}\text { Compou } \\
\text { nd } \\
\text { sodium } \\
\text { nitrophe }\end{array}$ & $\begin{array}{c}20.63 \pm 0.64 \\
b\end{array}$ & & & \\
\hline $\begin{array}{l}\text { nolate } \\
\text { diethyl }\end{array}$ & & $261.5 \pm 6.77 \mathrm{a}$ & $55.23 \pm 1.42 \mathrm{bc}$ & $704.75 \pm 14.31 \mathrm{~b}$ \\
\hline $\begin{array}{l}\text { aminoet } \\
\text { hyl } \\
\text { hexanoat }\end{array}$ & $\begin{array}{c}21.96 \pm 0.24 \\
\mathrm{a}\end{array}$ & & & \\
\hline $\begin{array}{c}\mathrm{e} \\
\alpha \text {-sodiu }\end{array}$ & & $243.19 \pm 3.38 b$ & $58.41 \pm 1.75 \mathrm{ab}$ & $701.36 \pm 18.07 \mathrm{~b}$ \\
\hline $\begin{array}{c}\mathrm{m} \\
\text { naphthal } \\
\text { ene }\end{array}$ & $\begin{array}{c}22.13 \pm 0.31 \\
\mathrm{a}\end{array}$ & & & \\
\hline acetate & & $262.62 \pm 3.77 \mathrm{a}$ & $61.13 \pm 2.19 \mathrm{a}$ & $801.77 \pm 18.66 \mathrm{a}$ \\
\hline
\end{tabular}

The Effects of Growth Regulators on Resistant Indexes of the Older Banana Planting Seedlings. As shown in table 3, compared with the control group, compound sodium nitrophenolate and gibberellin can all significantly increase chlorophyll content of the older banana planting seedlings by $33.82 \%$ and $19.11 \%$ respectively. MDA is the final breakdown product of plant membrane lipid peroxidation, the higher is its content, the more serious the damage to cell membrane is [21-22]. When proline content is increased, the resistance of plants to adversity will be increased [27]. It can be seen from Table 3 that, using plant growth regulator can significantly reduce the MDA content, and increase the proline content, on average, when reducing MDA content of $14.03 \%$,the proline content can be increased by $38.93 \%$ to $129.84 \%$. SOD and POD are two important components in the plant membrane protective enzyme system, the higher the active is, the better the protective function to biofilm will be, the stronger the ability of plants to withstand 
adversity will be[30]. Compared with the control group, gibberellin can significantly increase SOD and POD content of the older banana planting seedlings leaves by $21.94 \%$ and $82.13 \%$ respectively. Diethyl aminoethyl hexanoate can only increase POD content of the foliage by $23.36 \%$. Thus, during cultivating the older planting banana seedlings, gibberellin can effectively increase chlorophyll content, and reduce MDA content of the foliage, increase proline content, improve the activity of protective enzymes, which has better effect on resistances of the older banana planting seedlings than other growth regulators.

Table 3 The effects of growth regulators on resistant indexes of the older banana planting seedlings.

\begin{tabular}{|c|c|c|c|c|c|}
\hline $\begin{array}{c}\text { Treatme } \\
\text { nt }\end{array}$ & $\begin{array}{l}\text { chlorophyll } \\
\text { content (mg) }\end{array}$ & $\begin{array}{c}\text { MDA } \\
\text { content } \\
(\mu \mathrm{mol} / \mathrm{g})\end{array}$ & $\begin{array}{l}\text { proline } \\
\text { content } \\
(\mu \mathrm{g} / \mathrm{g})\end{array}$ & $\begin{array}{c}\text { The activity } \\
\text { of SOD } \\
(\mathrm{U} /(\mathrm{g} \bullet \\
\text { FW }))\end{array}$ & $\begin{array}{c}\text { The activity } \\
\text { of POD } \\
(\mathrm{U} /(\mathrm{g} \bullet \\
\min ))\end{array}$ \\
\hline $\begin{array}{l}\text { The } \\
\text { control } \\
\text { group }\end{array}$ & $1.51 \pm 0.04 \mathrm{~cd}$ & $16.22 \pm 0.10 \mathrm{a}$ & $4.29 \pm 0.18 \mathrm{e}$ & $\begin{array}{c}326.09 \pm 18.4 \\
2 \mathrm{~b}\end{array}$ & $\begin{array}{c}804.34 \pm 23.82 \\
\text { c }\end{array}$ \\
\hline $\begin{array}{l}\text { gibberell } \\
\text { in }\end{array}$ & $1.79 \pm 0.03 \mathrm{~b}$ & $\begin{array}{c}15.20 \pm 0.07 \\
b\end{array}$ & $8.56 \pm 0.19 b$ & $\begin{array}{c}397.62 \pm 5.67 \\
\mathrm{a}\end{array}$ & $\begin{array}{c}1464.91 \pm 32.6 \\
5 \mathrm{a}\end{array}$ \\
\hline $\begin{array}{l}\text { multi-eff } \\
\text { ect azole }\end{array}$ & $1.63 \pm 0.05 \mathrm{c}$ & $14.34 \pm 0.05 \mathrm{c}$ & $9.86 \pm 0.19 \mathrm{a}$ & $\begin{array}{c}321.60 \pm 13.3 \\
2 \mathrm{~b}\end{array}$ & $\begin{array}{c}858.51 \pm 26.73 \\
\mathrm{c}\end{array}$ \\
\hline $\begin{array}{l}\text { Compou } \\
\text { nd } \\
\text { sodium } \\
\text { nitrophe } \\
\text { nolate }\end{array}$ & $2.02 \pm 0.04 \mathrm{a}$ & $\begin{array}{c}13.14 \pm 0.23 \\
\mathrm{~d}\end{array}$ & $7.61 \pm 0.28 \mathrm{c}$ & $\begin{array}{c}380.68 \pm 6.68 \\
b\end{array}$ & $510.83 \pm 8.21 d$ \\
\hline $\begin{array}{l}\text { diethyl } \\
\text { aminoet } \\
\text { hyl } \\
\text { hexanoat } \\
\text { e }\end{array}$ & $1.38 \pm 0.04 \mathrm{de}$ & $12.15 \pm 0.23 \mathrm{e}$ & $5.84 \pm 0.19 \mathrm{~d}$ & $\begin{array}{c}379.23 \pm 4.18 \\
b\end{array}$ & $\begin{array}{c}922.21 \pm 29.96 \\
b\end{array}$ \\
\hline $\begin{array}{l}\alpha \text {-sodiu } \\
\text { m } \\
\text { naphthal } \\
\text { ene } \\
\text { acetate }\end{array}$ & $1.36 \pm 0.05 \mathrm{e}$ & $\begin{array}{c}14.88 \pm 0.44 \\
b\end{array}$ & $6.05 \pm 0.26 \mathrm{~d}$ & $\begin{array}{c}365.24 \pm 7.49 \\
\mathrm{~b}\end{array}$ & $\begin{array}{c}815.35 \pm 22.20 \\
\mathrm{c}\end{array}$ \\
\hline
\end{tabular}

\section{Discussion and Conclusion}

Plant growth regulator is a kind of chemical with high biological activation, which can promote the growth and development of a variety of crops, and increase their resistance. In this experiment, spraying a certain concentration of plant growth regulator, can improve plant morphology of the older banana planting seedlings, adjust agronomic traits, nutrient absorption and physiological resistance; and different plant growth regulators have different regulating effects.

Spraying $20 \mathrm{mg} / \mathrm{L}$ of gibberellin on the leaf of can promote the growth of the stem height and the top three leaf area, increase the chlorophyll content, effectively reduce MDA content, increase proline content, improve the activity of protective enzyme, and have better effect on resistances of the older banana planting seedlings than other growth regulators. The results are the same as the predecessors' research by Long Yifei and Deng Huihui, Li Hao-liang et at. [14-17]. Spraying 20 $\mathrm{mg} / \mathrm{L}$ of sodium on the leaf of can promote the stem height and stem diameter, increase dry matter cumulant and NPK nutrient uptake, increase the strong seedlings index. The results are similar to the research on chili by Zhang Hong-ju et al. [20]. Multi-effect azole, compound sodium 
nitrophenolate and diethyl aminoethyl hexanoate, these three kinds of growth regulators have different effects on the growth and physiological resistance, only specific aspects, which are not as significant as gibberellin and $\alpha$-sodium naphthalene acetate.

In summary, the results show that, during cultivating the older planting banana seedlings, spraying a certain concentration of gibberellin on the leaf, can increase the stem height, increase chlorophyll content, promote its morphology formation, improve resistances of the older banana planting seedlings; Spraying $\alpha$-sodium naphthalene acetate can improve the strong older seedling index and promote dry matter cumulant and nutrient uptake. Thus, during cultivating the older planting banana seedlings, only spraying gibberellin or $\alpha$-sodium naphthalene acetate separately can can have some effects; however, In order to get strong banana older planting banana seedlings, we should consider to mix gibberellin with $\alpha$-sodium naphthalene acetate, or spray them at certain intervals. As for the effects of specific spraying, more further researches are still needed.

\section{Acknowledgements}

Fund project: Chinese banana industry technology system Danzhou comprehensive experimental station (CARS32-16); The ministry of agriculture species resources protection project (tropical crops) (16 rzzy - 01); Non-profit scientific research institution reform professional start-up cost project (pzsfyl - 201709).

\section{References}

[1] Dong Tao, Chen Xin-jian et al. "the Main Problems Facing the Banana Industry in China and Countermeasures" [J]. Journal of Guangdong agricultural sciences, 2013 (11): 220-223.

[2] Wu Dai-dong, Wei Hua-fang Li Chao-sheng et al. "Practical Supporting Technology for Culture Tissue Banana Planting Seedlings under the High Temperature in Summer and Autumn" [J]. South China Fruits, 2008, 37 (6): 33-35.

[3] Lin Gui-mei, Li Xiao-quan, Wei Shao-long, et al. "Chinese Banana Chilling Injury Research and the Recovery Countermeasures in Spring of 2011" [J]. southern agriculture Journal, 2012, 43 (1) : 46-49.

[4] Li Mao-fu, Li Shao-peng, Wu Fan, et al. "Research Progress of Banana Frost-resistant "[J]. Journal of South China Tropical Agriculture University, 2005, 11 (01) : 51-54.

[5] Mou Hai-fei, Lin Gui-mei, Zou Yu, et al. Study on Different Ages of "B6 Williams" Rooting Tissue Banana Seedlings and the subsequent Planting Seedlings [J]. Northern Horticulture, 2011, (02): 135-138.

[6] Cheng Shimin, Fan Xiao-lin. "the Influence of Transplanting Seedling Age on Banana Harvest Time, Yield and Quality" [J]. Fruit Trees Journal, 2014, 31 (5): 879-884.

[7] Long Yifei. "Rapid Cultivating Media for Banana Planting Seedlings and Regulation Research" [D]. Guangdong, south China agricultural university, 2012.

[8] xin-ling zhang. Banana older false seeding cultivation regulation technology and its impact on banana flower bud differentiation [D]. Guangdong, South China Agricultural University, 2014.

[9] Wen Tinggang. " the Influence of Plant Growth Regulator on Wheat Lodging Resistance, Yield and Quality and the Physiological Mechanism “[D]. Jiangsu, Nanjing Agricultural University, 2012.

[10]Li dong, Zheng Dian-feng, Feng Nai-jie, et al. " the Influence of Plant Growth Regulator on Maize Grain, Yield and Fresh Weight "[J]. Southern Agriculture Journal, 2016, 47 (8) : 1285-1289.

[11] Chart Z. Expression profiling of ABA pathway Iranscripts indicates crosstalk between abiotic and bioti sess responsesin[J]. Arabidopsis Genomics, 2012, 100(2): 110-115.

[12]Kulkarnia Manoj G, Stirka Wendy A, et al. Plant growth regulators enhance gold uptake in Brassica juncea[J].Int J Phytoremediation, 2013,15(2):117-126.

[13] Yang Cui-qin, Qin Yao-guo, Tong Chuan.” the Influence of Different Media and Plant Growth Regulators on Hibiscus Cutting Wood Rooting" [J]. Northern Horticulture, 2012 (5): 88-90. 
[14]Deng Huihui, Bai Long-qiang, Yu Xian-chang, et al. The effects of spraying gibberellin on cucumber leaf in early spring greenhouse on growth and physiological and yield $[\mathrm{J}]$. Acta Horticulturae Sinica, 2016, 43 (5): 983-990.

[15]Li Sen, Zhao Yu, Dong Ai-xiang, et al. The effect of multi-effect azole on scarlet sage Potting seedlings quality [J]. Journal of Shanxi Agricultural University (natural science), 2007, 27 (4): 55 to 59

[16]Zhang Hong-ju, Zhao Huai-yong, YU Ji-hua, the efffects of $\alpha$-sodium naphthalene acetate on pepper production in the greenhouse and endogenous hormone levels [J]. Journal of Desert Research, 2013, 33 (5): 1390-1399.

[17] Hu Zhao-ping, Li wei, Chen Jian-qiu, et al. The effects of compound sodium nitrophenolate, DA - 6 and $\alpha$-sodium naphthalene acetate on yield and quality of eggplant [J]. Journal of Agriculture, 2013, 29 (25): 168-172.

[18]Zhang Zi-long, Liang Ying. The effects of DA - 6 on the rice seed germination and seedling growth [J]. Journal of Southwest Agricultural University, 2001, 23 (3): 219-221.

[19]Fan Yongbai. Older Banana Seedlings High-yield Cultivation Technology [J]. Guangdong Agricultural Sciences, 2001 (6): 25-26.

[20] Lu Ru-kun. Agricultural Chemical Analysis [M]. Beijing: China Agricultural Science and Technology Press, 2000

[21]Hao Jian-jun, Kang Zong-li, Yu Yang, Plant Physiology Experiment Technology [M]. Beijing: Chemical Industry Press, 2007:107-129.

[22]Zhou Zufu, Li Zhao-an. Plant Physiology Experiment Guidance [M]. Nanning: Guangxi University, 2005:102-117. 